\title{
Alterações Eletrocardiográficas Induzidas pela Hipotermia
}

\section{Hypothermia-Induced Electrocardiographic Changes}

Ana Marques, ${ }^{1 \oplus}$ Daniel Caldeira, ${ }^{2}$ Alexandra Briosa, ${ }^{1}$ Isabel João, ${ }^{1}$ Hélder Pereira ${ }^{1}$

Hospital Garcia de Orta EPE, ${ }^{1}$ Almada - Portugal

Centro Cardiovascular da Universidade de Lisboa - CCUL, Laboratório de Farmacologia Clínica e Terapêutica, Faculdade Medicina, Universidade de Lisboa, Lisboa - Portugal

Uma paciente idosa foi levada ao pronto-socorro devido à perda de consciência. Apresentava antecedentes pessoais de hipercolesterolemia e hipertensão essencial. A paciente não era tratada com nenhum medicamento cronotrópico negativo. Na hospitalização, a pressão arterial da paciente era de 90/60 mmHg, ela apresentava bradicardia (42 bat./ minuto) e hipotermia (33드). O eletrocardiograma (ECG) mostrou bradicardia sinusal, bloqueio atrioventricular de $1 \underline{0}$ grau, prolongamento do intervalo QT corrigido e ondas de Osborn ao final dos complexos QRS (Figura 1 A, pontas de seta). Dessa forma, essas deflexões positivas de entalhe foram melhor observadas nas derivações precordiais laterais e desapareceram após o aquecimento da paciente a $36^{\circ} \mathrm{C}$ (Figura 1 B). A bradicardia, o bloqueio atrioventricular e prolongamento do QT também foram resolvidos (Figura 1 B). Durante a internação, a tomografia computadorizada da cabeça, o Holter de 24 horas e a análise laboratorial não revelaram alterações significativas. O ecocardiograma transtorácico revelou apenas alterações degenerativas das válvulas aórtica e mitral. Este caso é ilustrativo de alterações eletrocardiográficas induzidas por hipotermia, especificamente, prolongamento dos intervalos PR, RR e QT e, principalmente, a presença de ondas de Osborn. ${ }^{1,2}$

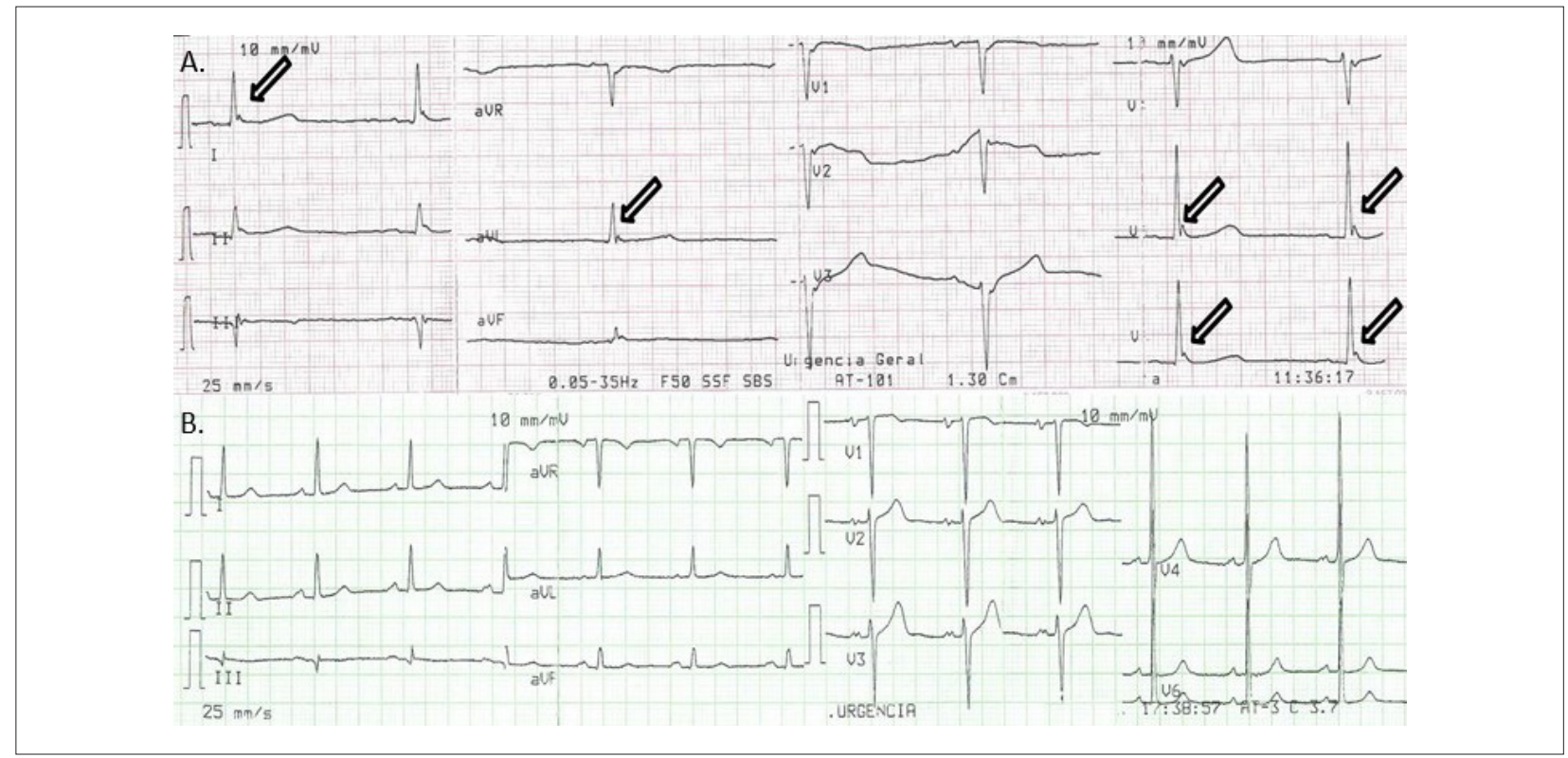

Figura 1 - Painel A) Eletrocardiograma (ECG) mostrando alterações de ECG induzidas por hipotermia: bradicardia sinusal, bloqueio atrioventricular de $1^{\circ}$ grau, pronlongamento do intervalo QT corrigido e ondas de Osborn no final dos complexos QRS (pontas de seta). Painel B) Após o aquecimento da paciente, o eletrocardiograma (ECG) mostra resolução das alterações eletrocardiográficas induzidas por hipotermia.

\section{Palavras-chave}

Bradicardia; Bloqueio Atrioventricular; Eletrocardiografia/ métodos; Hipotermia; Ondas Osborn.

Correspondência: Ana Marques •

Hospital Garcia de Orta EPE - Av. Torrado da Silva, 2801-951, Almada - Portugal

E-mail: ana.smc.25@gmail.com

Artigo recebido em 11/02/2020, revisado em 22/03/2020, aceito em

$22 / 03 / 2020$

DOI: https://doi.org/10.36660/abc.20200081 


\section{Referências}

1. Alhaddad IA, Khalil M, Brown EJ Jr. Osborn waves of hypothermia. Circulation. 2000;101(25):E233-E244.
2. Doshi HH, Giudici MC. The EKG in hypothermia and hyperthermia. I Electrocardiol 2015; 48(2):203-8. 